\title{
Why Gender is a Relevant Factor in the Social Epistemology of
}

\section{Scientific Inquiry?}

\author{
Kristina Rolin ${ }^{1}$
}

October 14, 2002

"Is Methodology Gendered - and Should It Be?" (Symposium)

The Eighteenth-Biennal Meeting of Philosophy of Science Association

\begin{abstract}
In recent years, feminist philosophy of science has been subjected to criticism. Much of the debate has focused on the implications of the underdetermination thesis for accounts of the role of social values in scientific reasoning. My aim here is to offer a different approach. I suggest that feminist philosophers of science contribute to our understanding of science by (1) producing gender sensitive analyses of the social dimensions of scientific inquiry and (2) examining the relevance of these analyses for normative issues in philosophy of science.
\end{abstract}

\footnotetext{
${ }^{1}$ Department of Philosophy, Helsinki School of Economics, P.O. Box 1210, 00101 Helsinki, Finland. I will not be able to present the paper in the meeting. For comments, please contact rolin@hkkk.fi.
} 


\section{Introduction}

In recent years, feminist epistemology and philosophy of science has been subjected to criticism. Cassandra Pinnick (1994) claims that feminist epistemology relies on a contested interpretation of Kuhn's and Quine's legacy. Even if we accept the underdetermination thesis, the claim that the choice of hypotheses and theories is not uniquely determined by empirical evidence, it does not follow that logical gaps in evidential reasoning must be filled by noncognitive values, she argues (Pinnick 1994, 651). According to Susan Haack, feminist philosophers argue that "evidence never obliges us to accept this claim rather than that, and we have to accept something, so acceptance is always affected by something besides the evidence, which had better be good, progressive values rather than bad, regressive values" $(1996,84)$. Haack points out that the second premise, the claim that scientists have to accept something as true, is false. Therefore, she argues, it does not follow that acceptance is always influenced by something besides evidence, be it progressive or regressive social values. Most recently, Noretta Koertge (2000) presents feminist philosophy of science as part of what she calls "'new age' philosophies of science." These philosophies, she claims, share a certain take on post-positivist philosophy of science: "They cite familiar philosophical discussions of the theory-ladenness of observation, the under-determination of theory by data, antirealist conceptions of scientific theories, and non-foundationalist accounts of observational or experimental data, and then construe them to be arguments that no interesting epistemic or methodological distinction can be drawn between scientific 'knowledge' and other systems of belief" (Koertge 2000, 668-69). 
These critics share the assumption that feminist philosophy of science is contingent on the view that noncognitive values are inevitably involved in evidential reasoning. They suggest that feminist philosophers appeal to a contested legacy of the underdetermination thesis, the claim that the logical gap between empirical evidence, on the one hand, and hypotheses and theories, on the other, is inevitably filled by noncognitive values. If arguments made by feminist philosophers are thus construed, it is indeed not difficult to point out their weaknesses. As the critics have repeatedly emphasized, the underdetermination thesis implies, at most, that it is possible for noncognitive values to enter into evidential reasoning. This, however, is not the same thing as to say that noncognitive values are allowed to do so or that they should do so, given the normative theories of scientific methodology that most contemporary philosophers of science embrace. ${ }^{2}$ Thus, the critics conclude that feminist philosophers make the mistake of inviting wishful thinking into scientific reasoning.

I think that there is more to be said of feminist philosophers' contributions to the debate about the role of noncognitive values in scientific reasoning (see Rolin forthcoming). The aim of this paper, however, is going to be something else. My aim is to offer a different approach to understanding what feminism can contribute to the philosophy of science. I suggest that feminist philosophers of science contribute to our understanding of science by (1) producing gender sensitive analyses of the social dimensions of scientific inquiry and (2) examining the relevance of these analyses for normative issues in the philosophy of science. The "gender and science" debate so far has

\footnotetext{
${ }^{2}$ Here the critics echo Larry Laudan's (1990) claim that sloppy formulations of the underdetermination thesis often rely on an outdated account of methodology, as if
} 
operated with a narrow understanding of the social dimensions of scientific inquiry. The "social" in science is understood to refer to scientists' "social," that is, noncognitive, values and interests. Consequently, the debate has focused on the question "What different roles can scientists' noncognitive values and interests play in scientific reasoning (given various versions of the underdetermination thesis), and what roles are they allowed to play?"

In this paper, I explore some other social dimensions of scientific inquiry that are of epistemic interest, namely, trust among scientists, dynamics of communication within scientific communities, and distribution of research effort. Recent insights from the social epistemology of scientific inquiry enable me to argue that gender can play both a negative and a positive role in scientific inquiry. Gender plays a negative role when gender bias interferes with scientists' evaluations of their colleagues' trustworthiness or when the gendered dynamics of communication function as obstacles to inclusive and critical dialogue, thus impeding scientists' ability to realize their epistemic goals. Gender plays a positive role when sensitivity to gender bias generates a distribution of research effort, thereby increasing the likelihood that alternative theories and hypotheses will be developed and tested. In the first case, gender is, paradoxically, relevant for the social epistemology of scientific inquiry in the sense that it should not be relevant for scientific inquiry. In the second case, gender is relevant for the social epistemology of scientific inquiry in another sense. The epistemically relevant factor is not gender bias as such, but the sensitivity of researchers to gender bias in its various manifestations. Such a sensitivity can play a positive role in some areas of inquiry, but perhaps not in all.

methodology is exhausted by rules of deductive logic or simple induction alone. 


\section{Social epistemology of scientific inquiry}

In addition to the "social values and interests" approach, where "social" is understood to refer to scientists' noncognitive values and interests, we can distinguish two other ways of understanding the "social" in science. One way of understanding the "social" in science is to focus on relations between scientists; another is to focus on scientific communities as units of epistemic appraisal. As philosophers of science know, to claim that "science is a social practice" is not yet to say anything philosophically interesting. The challenge is to distinguish those social dimensions which contribute either positively or negatively to the epistemic success of science from those which have no epistemic significance. Next, I will present a brief overview of arguments which aim to establish that some relations between scientists and some features of communities are of epistemic importance.

John Hardwig (1985 and 1991) argues that trust among scientists is of epistemic importance. He suggests that scientific methodology should be adjusted to the view that in some situations a scientist can legitimately justify her belief by trusting another scientist's word. These situations arise when the cost of doing the research on her own is too high or impossible to meet. In present day science, which is characterized by an advanced division of labor and specialization, these situations are not rare. As Philip Kitcher (1990, 1992 and 1993) points out, the division of labor and specialization have the consequence that trust becomes the only practical alternative to either ignorance or stagnation of research. What is required, however, is not simply trust, but trust based on justified confidence in other scientists' cognitive authority in their respective domains of expertise. 
Hardwig's and Kitcher's analysis of the epistemic importance of trust, if correct, gives rise to interesting research problems, both descriptive and normative. Descriptive studies of science could explore the factors that guide scientists' perceptions of their colleagues' credibility and reputation. Normative studies could address such questions as "Under what conditions is it rational for one scientist to trust another?" Or: "When is it more rational to rely on an expert instead of doing the research on one's own?"目

Trust is of epistemic importance not only because it is allowed to ground scientists' beliefs (at least some beliefs in some situations), but also because it shapes the social dynamics of communication within scientific communities. For example, failure to recognize another scientist's cognitive authority may ultimately lead a scientist to ignore relevant evidence or criticism presented by her colleague. Helen Longino argues that the social dynamics of communication is of epistemic importance because the assessment of evidence and reasoning is often part of a practice of challenge and response $(2002,103) .{ }^{\text {G }}$ Besides more traditional methodological norms, a normative account of scientific knowledge should include norms governing such practices, she suggests $(2002,129)$. Such norms should be designed so that they facilitate inclusive and critical dialogue. An

\footnotetext{
${ }^{3}$ For a critique of Hardwig's approach to the social epistemology of scientific inquiry, see Rolin (2002). Whereas Hardwig and Kitcher focus on trust among experts, Alvin Goldman (2002) addresses the novice/expert problem. For a more general debate about the epistemic justification of testimony, see Coady (1992), Fricker (1995), and Kusch (2002).

${ }^{4}$ Longino makes also a stronger claim than this, arguing that epistemic justification must be social because the main components of justification, observation and reasoning, are dialogical, that is, "activities involving discursive interactions among different voices" (2002, 99; see also 134). In her argument, she appeals to a version of the underdetermination thesis $(2002,124-28)$. However, the epistemic importance of communication can be defended by appealing to the weaker claim that in scientific communities epistemic justification often involves a practice of challenge and response.
} 
inclusive and critical dialogue is an epistemic ideal, Longino argues, since it reduces the likelihood that the outcome of debate reflects merely the biases and idiosyncratic preferences of a subcommunity $(2002,134)$. Longino also offers a tentative list of norms which define a set of rights and respective duties for members of a scientific community. A descriptive counterpart to Longino's normative project could explore the actual social dynamics of communication within and across scientific communities, in order to find out what social arrangements facilitate inclusive and critical dialogue.

Another approach to the social epistemology of scientific inquiry focuses on the distribution of research effort within scientific communities. Philip Kitcher (1990 and 1993) and Miriam Solomon (1992 and 2001) argue that in some situations scientists' noncognitive values and interests can contribute positively to the development of science by facilitating a distribution of research effort. ${ }^{6}$ These situations arise when many theories or research programs have some empirical successes and none of the theories and research programs has all available empirical successes. Empirical successes can come in

\footnotetext{
${ }^{5}$ Longino claims that the following four norms are necessary to assure the effectiveness of discursive interactions: "There must be publicly recognized forums for the criticism of evidence, of methods, and of assumptions and reasoning" (2002, 129). "There must be uptake for criticism" $(2002,129)$. "There must be publicly recognized standards by reference to which theories, hypotheses, and observational practices are evaluated and by appeal to which criticism is made relevant to the goals of the inquiring community" $(2002,130)$. "Finally, communities must be characterized by equality of intellectual authority" (2002, 131). In Fate of Knowledge (2002), Longino presents a tempered version of the fourth condition by adding several qualifications which are not mentioned in Science as Social Knowledge (1990).

${ }^{6}$ Solomon makes also a stronger claim than this, suggesting that a social epistemology of scientific inquiry should evaluate the distribution of research effort within scientific communities instead of evaluating the choices and actions of individual scientists (2001, 120). However, we can appreciate the insight that scientists' noncognitive values and interests can sometimes play a positive role in scientific inquiry by facilitating a
} 
many forms, e.g. as successful predictions of new phenomena, new explanations of already known phenomena, and successful control and manipulation of processes (Solomon 2001, 27). As long as none of the theories and research programs has all available empirical successes, it is rational to distribute research effort so that each theory or research program receives its fair share of attention (Solomon 2001, 76-77 and 11718). A distribution of research effort among those theories and research programs which have some empirical successes will ensure that scientists examine rigorously the strengths and weaknesses of rival positions, thus enabling them as a community to arrive at a more successful theory. As Kitcher points out, "scientific debates are resolved through the public articulation and acceptance of a line of reasoning that takes considerable time to emerge" (1993, 344), and "the working out of this line of reasoning depends crucially on the presence in the community of people who are prepared to work and defend rival positions" $(1993,344)$. If Kitcher's and Solomon's analysis of the epistemic importance of distributing research effort is correct, then a social epistemology of scientific inquiry could aim to determine what social and psychological factors generate and maintain such a division of labor. Kitcher (1993) suggests that a distribution of research effort can be encouraged by the social system of rewards, sanctions, and competitive pressures. Such a system can channel scientists' noncognitive values and interests, such as the thirst for fame and fortune, to serve the epistemic ends of the community. Solomon (1992) suggests that a distribution of research effort is sustained by cognitive biases, such as salience bias and belief perseverance, which have previously been seen merely as weaknesses of the 
human mind. In her most recent work, she suggests that the distribution of research effort should be a guiding principle of science policy (Solomon 2001).

The arguments I have sketched here support the claim trust among scientists, dynamics of communication within scientific communities, and distribution of research effort are of epistemic importance. They also provide an alternative analysis of the social dimensions of scientific inquiry to the approach where the focus is on the implications of the underdetermination thesis for the role of scientists' "social" values and interests in scientific reasoning. None of the arguments I have sketched here appeals to the contested claim that the logical gap between empirical evidence, on the one hand, and hypotheses and theories, on the other, is inevitably filled by noncognitive values. Instead, the arguments elaborate on the insight that the cooperative engagement of many scientists, within and across disciplines, has contributed to the epistemic success of science. Each of the arguments is also based on the view that scientific methodology should come to terms with the limits of human cognitive capacities. It is claimed that trust has epistemic significance because human beings, by virtue of their limited cognitive capacities, are not capable of mastering large domains of scientific knowledge. It is claimed that communication has epistemic significance because human beings, by virtue of their limited cognitive capacities, are not capable of reflecting on their biases, prejudices, and idiosyncratic preferences on their own. Finally, it is claimed that the distribution of research effort has epistemic significance because human beings, by virtue of their limited cognitive capacities, cannot be expected to follow every plausible line of inquiry.

I have argued also that the above analysis of the social dimensions of scientific inquiry gives rise to interesting research problems. Much research is needed to explore the 
factors that guide scientists' understanding of credibility, the actual social dynamics of communication, and the factors that generate and maintain a distribution of research effort within scientific communities. Next, I will argue that such research should not ignore gender.

3. Gender, credibility, and the social dynamics of communication

Several historical studies of science suggest that there is a long tradition of gender bias in the evaluation of intellectual competence (Nye 1997; Rossiter 1982, 1993, and 1995; Schiebinger 1989; Shapin 1994). But also studies of contemporary science suggest that gender bias influences scientists' perceptions of intellectual competence. These studies fall roughly into three categories. Some studies attempt to document scientists' understanding of gender and credibility on the basis of qualitative data, such as observations made in field work and interview data. Others attempt to form a more objective picture of gender and credibility by analyzing quantitative data on the outcome of funding and hiring decisions. A third category of studies tries to capture the social dynamics of communication by focusing on gender and citations.

Qualitative data on gender and credibility can be found in Sharon Traweek's Beamtimes and Lifetimes (1988) and Gerhard Sonnert's and Gerald Holton's Gender Differences in Scientific Careers (1995). ${ }^{\text {Both of these studies offer interesting }}$

\footnotetext{
${ }^{7}$ Traweek's Beamtimes and Lifetimes is a comparative ethnographic study of American and Japanese high energy physics communities. Sonnert's and Holton's Gender Differences in Scientific Careers analyzes the results of the Project Access study for
} 
information on scientists' stereotypical perceptions of a successful scientist even though they do not focus on this aspect of science alone. They suggest that credibility is associated with combative style of communication which, in turn, is associated with a certain notion of masculinity (Traweek 1988, 87-88; Sonnert and Holton 1995, 144-45). Both of these studies suggest that these associations put female and male scientists into unequal positions. ${ }^{\text {G }}$ Sonnert and Holton report also that the female scientists interviewed in their study often felt excluded from informal social networks in their fields (1995, 13132). And the female scientists' feelings of exclusion and marginalization were not merely subjective; after their postdoctoral fellowship years, the female scientists have had less access to collegial collaborations than the men who participated in the study $(1995,135)$. A recent report from MIT suggests that even those women scientists who have been successful in securing a tenured position in a prestigious institution suffer from marginalization in their institutions and communities (Committee on Women Faculty in the School of Science at MIT, 1999).

which two hundred men and women scientists with prestigious postdoctoral fellowships were interviewed in the late 1980s and early 1990s.

${ }^{8}$ Andrea Dupree makes a similar observation in an interview with Harriet Zuckerman and Jonathan R. Cole (Zuckerman and Cole 1991, 103).

${ }^{9}$ The gendered nature of aggression and competition in science is also recognized by David Hull $(1988,390)$. See Kourany (1998) for a critical discussion of Hull's work.

${ }^{10}$ Recent years have witnessed an emergence of studies which document and analyze female scientists' and academics' experiences of exclusion and marginalization (see e.g., Caplan 1994; Collins et al. 1998; Husu 2001; Katila and Meriläinen 1999; Pattatucci 1998). These studies suggest that subtle forms of discrimination can limit women's opportunities to participate in scientific dialogue. For example, they may create a "chilly climate" where women's contributions to scientific debate go unnoticed, or where women do not feel comfortable in informal social gatherings, and consequently, miss opportunities for academic discussion and collaboration. 
Quantitative data on gender bias in the evaluation of scientific competence can be found in two articles, Rhea Steinpreis'es, Katie Anders'es and Dawn Ritzke's "The Impact of Gender on the Review of the Curricula Vitae of Job Applicants and Tenure Candidates: A National Empirical Study" (1999) and Christine Wennerås'es and Agnes Wold's "Nepotism and Sexism in Peer-review" (1997). Steinpreis, Anders and Ritzke (1999) gathered data by sending a questionnaire and a curriculum vitae with either a traditional male or female name to 582 US psychologists, both males and females. On the basis of the 238 responses they received, they found that both men and women were more likely to vote to hire a male job applicant than a female job applicant with an identical record. 11 Wennerås and Wold (1997) investigated how the peer-reviewers of the Swedish Medical Research Council (MRC) had actually evaluated women's and men's applications for postdoctoral fellowships during the early 1990s. When they compared the competence ratings of the MRC to six alternative measures of competence, each reflecting the number and the impact factor of the applicant's scientific publications, they found that female and male applicants with equal scientific productivity did not receive the same ratings from the peer-reviewers of the national council. They also argue that such factors as nationality, the field of the first university degree, and the speciality could not have accounted for the unequal ratings of male and female applicants. This, they argue, shows that the peerreviewers were not able to judge scientific competence independently of the applicant's gender and academic affiliations.

\footnotetext{
${ }^{11}$ I am grateful to K. Brad Wray for drawing my attention to the study of Steinpreis, Anders and Ritzke.
} 
A third category of studies focuses on citations as a measure of scientists' credibility and visibility in their fields. Studies of gender and citations suggest that the impact of gender bias on citations varies from one field to another. For example, Marianne Ferber (1986 and 1988) finds evidence of gender bias in citations in the fields of labor economics, financial economics, developmental psychology, mathematics, and sociology. She reports that in each of the five fields, references to women's publications constitute a larger percentage of all citations among women authors than men authors. J. Scott Long (1992) suggests that the smaller number of citations received by female scientists may result not from gender bias in citations but from the fact that female scientists, on the average, have fewer publications than their male colleagues. He reports that in biochemistry the average paper of a female scientist is actually cited more frequently than the average paper of the male scientist even though female scientists, on the average, publish less than their male peers.

It is important not to overstate the implications of these studies. On the basis of these studies, we do not know how widespread the stereotypical perception of a successful scientist as aggressive is. Moreover, even if scientists express stereotypical views in an interview or in a casual conversation, we do not know whether these views play a role in their decisions to trust another scientist's work or to engage him or her in a critical dialogue. Nor do we know whether the results of the study of Steinpreis, Anders and Ritzke (1999) or that of Wennerås and Wold (1997) could be generalized over other disciplines and other national contexts. And we do not know whether the gender bias exhibited in the context of funding and hiring decisions extends its influence over other 
contexts, such as decisions to cite someone's work in support of one's own. ${ }^{12}$ Finally, it is not clear whether citations offer a reliable measure of trust and willingness to enter into a genuine dialogue since scientific works are cited for many purposes. The studies I have mentioned here leave these questions unanswered. Nevertheless, I would argue that they have sufficient evidence of gender bias in perceptions of credibility to suggest that future studies on trust and the social dynamics of communication in science should not ignore gender as one factor that might have an impact on scientists' decisions to rely on their colleagues' work or to engage them in a genuine dialogue.

\section{Gender sensitive research and the distribution of research effort}

In section 2, I have argued that if the distribution of research effort contributes positively to the development of science, then a social epistemology of scientific inquiry could aim to determine what social and psychological factors generate and maintain cognitive diversity within scientific communities. In this section, I will argue that studies of cognitive diversity in scientific communities should pay attention to the role of gender sensitive research.

An example of such a study would be Alison Wylie's (1996) research on the emergence of the "archeology of gender" in the 1980s. She argues that the deliberate efforts on the part of some US archeologists to focus research on questions about gender

\footnotetext{
${ }^{12} \mathrm{~K}$. Brad Wray (2001) has recently argued that even if gender bias is pervasive in the context of funding and hiring decisions, it may have little or no consequences in the context where scientists make decisions to rely on others' work. The reason for this, he
} 
and women in prehistory led to significant contributions. Their efforts gave rise to a body of work which challenged the sexist and androcentric presuppositions which have guided earlier research, brought into light new evidence, and developed new interpretations of old evidence. As an example of research which challenged sexist assumptions, Wylie discusses Patty Watson's and Mary Kennedy's work on the development of horticulture in North America. Watson and Kennedy argue that earlier accounts of the emergence of agriculture in North America had relied on the assumption that prehistoric women could not have been the agents of culture-transforming innovations such as the development of new cultigens (Wylie 1996, 329-30). They point out that this assumption is in contradiction with another assumption, the belief that women were in charge of horticulture (Wylie 1996, 333). Moreover, they argue that it is highly implausible to suggest that new cultigens could have flourished without human agency (Wylie 1996, 334). As an example of research which exploited new evidence, Wylie (1996) discusses Christine Hastorf's work on the gendered division of labor in the central Andes before and during the Inca conquest of the region. Hastorf brought into light evidence of sex differences in human bone composition to support the hypothesis that the Inca conquest of the region had a profound impact on gender roles (Wylie 1996, 330). Finally, as an example of work which developed new interpretations of old evidence, Wylie mentions Russell Handsman's critique of gender ideologies that had informed earlier interpretations of prehistoric art (Wylie 1996, 332). In conclusion, Wylie suggests that "there could

argues, is that when scientists are looking for findings that support their own work, their self-interests are likely to override their biases. 
hardly be a more explicit case of political interests playing a crucial role in shaping the direction of research" $(1996,321)$.

Wylie's analysis of the role of gender sensitive research in archeology suggests that philosophers should seriously consider the hypothesis that sensitivity to gender and gender bias can play a positive role in science by generating a distribution of research effort. This hypothesis is quite different from the view that is often assigned to feminist philosophy of science, namely, the claim that women or feminists do or would do better science (see Pinnick 2000, 284). The hypothesis I invite philosophers to consider concerns not women or feminists as such but sensitivity to gender and gender bias in its various manifestations. Such a sensitivity can be cultivated by both male and female, feminist and non-feminist scientists alike. In fact, recent scholarship on feminism and science suggests that the interconnections between women's participation in science, feminism in science, and gender sensitive research can be quite complex. For example, studies of recent developments in archeology (Wylie 2001), primatology (Fedigan 2001), and developmental biology (Keller 1997 and 2001; Gilbert and Rader 2001) suggest that not all scientists doing gender sensitive research are women and feminists. Wylie suggests that even when scientists are not explicitly committed to feminism, their research program can be characterized as "feminist" if it aims to "prevent gender from being disappeared" (2001, 28). Londa Schiebinger (1999) argues that the influx of women into sciences will not automatically give rise to gender sensitive research. Recent history of US medicine is a case to the point. According to Schiebinger, the entry of women into the profession was only one factor among many others, including changing attitudes towards women in society, the emergence of the women's health movement, changes in legislation, and the 
intervention of Congress, that urged mainstream medicine to pay more attention to women's health concerns and to adopt the practice that female subjects are included in medical testing and research (1999, 121-25). Evelyn Fox Keller argues that in developmental biology the influx of women into the field changed the content of science not because women brought traditionally feminine or feminist values into their practice of science but because their presence "has helped erode the meaning of traditional gender labels in the very domain in which they worked, and for everyone in that domain" (2001, 105).

I do not claim either that scientists with sensitivity to gender and gender bias will always do better science. Instead, I would invite philosophers to consider the more modest hypothesis that sensitivity to gender and gender bias can play a positive role in science by

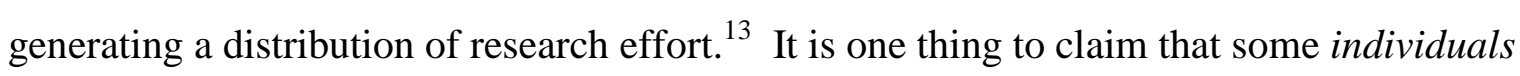
do or would do better science than others, and quite another thing to claim that communities which make room for cognitive diversity are epistemically more successful than those communities which do not. Both claims are empirical hypotheses in need of evidential support but the evidence needed to support them is different in each case. Whereas in the former case we would have to evaluate individual scientists' contributions to science, in the latter case we would have to look at how scientific debates have

\footnotetext{
${ }^{13}$ Solomon suggests that feminist standpoint theories could be reformulated as hypotheses concerning social factors which generate a distribution of research effort in science (2001, 141-42). It would be interesting to explore whether Keller's (1985) work on different styles of doing science could be reinterpreted as an analysis of psychological factors which contribute to cognitive diversity within scientific communities. See Martin (1988) for a discussion of Keller's work along these lines.
} 
progressed in certain communities over a period of time. ${ }^{14}$ The hypothesis I propose would require the latter strategy. Much work, of course, remains to be done to analyse in detail whether and how gender sensitive scholarship has contributed to the progress of scientific debates in various academic fields.

5. Conclusion: Why gender is a relevant factor in the social epistemology of scientific inquiry?

The critics of feminist philosophy of science assume that feminist philosophy of science is dependent on a contested legacy of the underdetermination thesis, the claim that noncognitive values are inevitably involved in evidential reasoning. In this paper I have argued that this assumption is false. I have suggested that feminist philosophy of science can contribute to our understanding of science by producing gender sensitive analyses of the social dimensions of scientific inquiry. In this paper I have focused on two dimensions, trust and communication among scientists and the distribution of research effort within scientific communities. I have sketched the arguments that have been presented in support of the claim that both of these two dimensions have epistemic significance, and I have argued that gender is a relevant factor in descriptive studies which explore these social dimensions of scientific inquiry. This analysis is by no means meant to be exhaustive of either gender in science or the social dimensions of science.

\footnotetext{
${ }^{14} \mathrm{~K}$. Brad Wray's manuscript "Understanding the epistemic value of women scientists" has helped me to formulate the distinction between these two hypotheses.
} 
As I have shown elsewhere (Rolin 1999), early works in feminist philosophy of science were burdened by overarching and global claims about gender and science. Some of these works tried to argue, on the basis of a speculative grand narrative about sexual division of labor (e.g., Harding 1986) or human cognitive and emotional development (e.g., Keller 1985), that all scientists understand nature to be feminine and science to be masculine. I have argued, instead, that claims about gender and science should be reformulated as more modest hypotheses concerning scientists' understanding of masculinity and femininity. In order for these hypotheses to have empirical content, we need to specify what aspects of scientific practices are understood to be gendered (e.g., metaphors, intellectual virtues, styles of communication), by whom they are understood to be gendered, and in what context (e.g., textbooks, casual conversations, assessment of theories).

The studies I have discussed here offer this kind of local and contextualized evidence of gender ideologies in science. Even though these studies do not license any overarching and global claims about gender and science, they are no less interesting. They suggest that future studies on trust, dynamics of communication, and cognitive diversity in science should not ignore gender. They also draw our attention to different aspects of the complex phenomenon we call "gender." In the first category of studies I have discussed here, the aspect of "gender" that is relevant for understanding science is gender bias (e.g., the association of credibility with masculinity). Such a bias may be shared by both male and female scientists alike. In the second category of studies, the aspect of "gender" that is relevant for understanding of science is the capacity to interpret and make explicit gender ideologies that are embedded in scientific theories and research programs 
as tacit assumptions. This capacity may be cultivated by both male and female scientists alike.

What implications, if any, does this analysis have for normative study of scientific knowledge? Is gender a relevant factor in methodology of science? As a normative study of scientific knowledge, the social epistemology of scientific inquiry is not meant to displace more traditional methodological concerns. Instead, it is meant to support and complete more traditional methodological norms by providing codes for social practices in science. If methodology is understood in the broad sense to include such codes, then gender is a relevant factor in the methodology of science for two reasons. First, gender is a relevant factor in the methodology of science insofar as gender bias interferes with scientists' understanding of credibility or stands in the way of inclusive and critical dialogue, thus impeding scientists' ability to realize their epistemic goals. In this case, gender is relevant in the methodology of science in the sense that it should not be relevant for scientific inquiry. Second, gender is a relevant factor in the methodology of science insofar as gender sensitive inquiry contributes to the distribution of research effort, thus increasing the likelihood that alternative theories will be developed and tested. In this case, gender is relevant in the methodology of science in the sense that it should be relevant for scientific inquiry - perhaps not in all disciplines but at least in some areas of scientific inquiry. 
References

Caplan, Paula. 1994. Lifting a ton of feathers: A woman's guide to surviving in the academic world. Toronto, Buffalo, and London: University of Toronto Press.

Coady, C. A. J. 1992. Testimony: A philosophical study. Oxford, UK: Oxford University Press.

Collins, Lynn H., Joan C. Chrisler, and Kathryn Quina, (ed.). 1998. Career strategies for women in academe: Arming Athena. Thousand Oaks: SAGE Publications.

Committee on Women Faculty in the School of Science at MIT. 1999. A study of the status of women faculty in science at MIT. The MIT Faculty Newsletter 11 (4): 117. http://web.mit.edu/fnl/women/women.pdf

Fedigan, Linda Marie. 2001. The paradox of feminist primatology: The goddess's discipline? In Angela N. H. Creager, Elizabeth Lunbeck, and Londa Schiebinger, (ed.), Feminism in twentieth-century science, technology, and medicine. Chicago and London: The University of Chicago Press, 46-72.

Ferber, Marianne A. 1986. Citations: Are they an objective measure of scholarly merit? Signs 11 (2): 381-89.

—. 1988. Citations and networking. Gender \& Society 2 (1): 82-89.

Fricker, Elizabeth. 1995. Telling and trusting: Reductionism and anti-reductionism in the epistemology of testimony. Mind 104 (414): 393-411.

Gilbert, Scott F., and Karen A. Rader. 2001. Revisiting women, gender, and feminism in developmental biology. In Angela N. H. Creager, Elizabeth Lunbeck, and Londa 
Schiebinger, (ed.), Feminism in twentieth-century science, technology, and medicine. Chicago and London: The University of Chicago Press, 73-97.

Goldman, Alvin I. 2002. Pathways to knowledge: Private and public. Oxford: Oxford University Press.

Haack, Susan. 1996. Science as social? Yes and no. In Lynn Hankinson Nelson and Jack Nelson, (ed.), Feminism, science, and the philosophy of science. Dordrecht: Kluwer Academic Publishers, 79-93.

Harding, Sandra. 1986. The science question in feminism. Ithaca: Cornell University Press.

Hardwig, John. 1985. Epistemic dependence. Journal of Philosophy 82 (7): 335-49.

—. 1991. The role of trust in knowledge. Journal of Philosophy 88 (12): 693-708.

Hull, David L. 1988. Science as a process: An evolutionary account of the social and conceptual development of science. Chicago and London: The University of Chicago Press.

Husu, Liisa. 2001. Sexism, support and survival in academia: Academic women and hidden discrimination in Finland. Doctoral dissertation, Department of Sociology, University of Helsinki.

Katila, Saija, and Susan Meriläinen. 1999. A serious researcher or just another nice girl? Doing gender in a male-dominated scientific community. Gender, Work and Organization 6 (3): 163-73.

Keller, Evelyn F. 1985. Reflections on gender and science. New Haven and London: Yale University Press.

—. 1997. Developmental biology as a feminist cause? Osiris 12: 16-28. 
—. 2001. Making a difference: Feminist movement and feminist critiques of science. In Angela N. H. Creager, Elizabeth Lunbeck, and Londa Schiebinger, (ed.), Feminism in twentieth-century science, technology, and medicine. Chicago and London: The University of Chicago Press, 98-109.

Kitcher, Philip. 1990. The division of cognitive labor. Journal of Philosophy 87 (1): 5-22.

—. 1992. Authority, deference, and the role of individual reasoning in science. In Ernan McMullin, (ed.), The social dimensions of science. Notre Dame, Indiana: University of Notre Dame Press.

—. 1993. The advancement of science: Science without legend, objectivity without illusions. Oxford: Oxford University Press.

Koertge, Noretta. 2000. 'New age' philosophies of science: Constructivism, feminism, and postmodernism. British Journal for Philosophy of Science 51: 667-83.

Kourany, Janet. 1998. A new program for philosophy of science, in many voices. In Janet Kourany, (ed.), Philosophy in a feminist voice: Critiques and reconstructions. Princeton: Princeton University Press, 231-262.

Kusch, Martin. 2002. Knowledge by agreement: The programme of communitarian epistemology. Oxford: Oxford University Press.

Laudan, Larry. 1990. Demystifying underdetermination. In C. Wade Savage, (ed.), Scientific theories, volume 14 of Minnesota Studies in the Philosophy of Science. Minneapolis: University of Minnesota Press, 267-297.

Long, J. Scott. 1992. Measures of sex differences in scientific productivity. Social Forces 71 (1): 159-78. 
Longino, Helen E. 1990. Science as social knowledge: Values and objectivity in scientific inquiry. Princeton: Princeton University Press.

—. 2002. The fate of knowledge. Princeton: Princeton University Press.

Martin, Jane R. 1988. Science in a different style. American Philosophical Quarterly 25 (2): $129-40$.

Nye, Robert A. 1997. Medicine and science as masculine "fields of honor." Osiris 12: 6079.

Pattatucci, Ángela M. 1998. Women in science: Meeting career challenges. Thousand Oaks, London and New Delhi: SAGE Publications.

Pinnick, Cassandra. 1994. Feminist epistemology: Implications for philosophy of science. Philosophy of Science 61: 646-657.

—. 2000. Veritistic epistemology and feminist epistemology: A-rational epistemics? Social Epistemology 14 (4): 281-91.

Rolin, Kristina. 1999. Can gender ideologies influence the practice of the physical sciences? Perspectives on Science 7 (4): 510-33.

—. 2002. Gender and trust in science. Hypatia 17 (4): [in press].

—. Forthcoming. Is 'Science as Social' a feminist insight? Social Epistemology.

Rossiter, Margaret W. 1982. Women scientists in America: Struggles and strategies to 1940. Baltimore and London: The Johns Hopkins University Press.

—. 1993. The Matthew Matilda effect in science. Social Studies of Science 23 (2): 32541.

—. 1995. Women scientists in America: Before affirmative action, 1940-1972. Baltimore and London: The Johns Hopkins University Press. 
Schiebinger, Londa. 1989. The mind has no sex? Women in the origins of modern science.

Cambridge, MA: Harvard University Press.

—. 1999. Has feminism changed science? Cambridge, MA, and London: Harvard University Press.

Shapin, Steven. 1994. A social history of truth: Civility and science in seventeenthcentury England. Chicago: The University of Chicago Press.

Solomon, Miriam. 1992. Scientific rationality and human reasoning. Philosophy of Science 59 (3): 439-55.

—. 2001. Social empiricism. Cambridge, MA: MIT Press.

Sonnert, Gerhard, with the assitance of Gerald Holton. 1995. Gender differences in science careers: The Project Access study. New Brunswick, NJ: Rutgers University Press.

Steinpreis, Rhea E., Katie A. Anders, and Dawn Ritzke. 1999. The impact of gender on the review of the curricula vitae of job applicants and tenure candidates: A national empirical study. Sex Roles 41: 509-528.

Traweek, Sharon. 1988. Beamtimes and lifetimes: The world of high energy physics. Cambridge, MA: Harvard University Press.

Wennerås, Christine, and Agnes Wold. 1997. Nepotism and sexism in peer-review. Nature 387 (May 22): 341-43.

Wray, K. Brad. 2001. Evaluating scientists. Paper presented at the conference on "Value Free Science: An Ideal or Illusion?" at the University of Alabama, Birmingham. 
Wylie, Alison. 1996. The constitution of archeological evidence: Gender politics and science. In Peter Galison and David J. Stump, (ed.), The disunity of science: Boundaries, contexts, and power. Stanford: Stanford University Press, 311-343.

—. 2001. Doing social science as a feminist: The engendering of archeology. In Angela N. H. Creager, Elizabeth Lunbeck, and Londa Schiebinger, (ed.), Feminism in twentieth-century science, technology, and medicine. Chicago and London: The University of Chicago Press, 23-45.

Zuckerman, Harriet, and Jonathan R. Cole. 1991. Interview with Andrea Dupree. In Harriet Zuckerman, Jonathan R. Cole, and John T. Bruer, (ed.), The outer circle: Women in the scientific community. New Haven: Yale University Press, 94-126. 